\title{
Colon Undifferentiated Carcinoma
}

National Cancer Institute

\section{Source}

National Cancer Institute. Colon Undifferentiated Carcinoma. NCI Thesaurus. Code C7100.

An invasive malignant epithelial tumor that arises from the colon. There is no morphologic, immunophenotypic, or molecular biological evidence of glandular or squamous differentiation. 